\title{
The effect of warmed inspired gases on body temperature during arthroscopic shoulder surgery under general anesthesia
}

\author{
Youn Yi Jo, Hong Soon Kim, Young Jin Chang, Soon Young Yun, and Hyun Jeong Kwak \\ Department of Anesthesiology and Pain Medicine, Gachon University Gil Medical Center, Incheon, Korea
}

Background: Perioperative hypothermia can develop easily during shoulder arthroscopy, because cold irrigation can directly influence core body temperature. The authors investigated whether active warming and humidification of inspired gases reduces falls in core body temperature and allows redistribution of body heat in patients undergoing arthroscopic shoulder surgery under general anesthesia.

Methods: Patients scheduled for arthroscopic shoulder surgery were randomly assigned to receive either room temperature inspired gases using a conventional respiratory circuit (the control group, $\mathrm{n}=20$ ) or inspired gases humidified and heated using a humidified and electrically heated circuit (HHC) (the heated group, $\mathrm{n}=20$ ).

Results: Core temperatures were significantly lower in both groups from $30 \mathrm{~min}$ after anesthesia induction, but were significantly higher in the heated group than in the control group from 75 to $120 \mathrm{~min}$ after anesthesia induction.

Conclusions: In this study the use of a humidified and electrically heated circuit did not prevent core temperature falling during arthroscopic shoulder surgery, but it was found to decrease reductions in core temperature from 75 min after anesthesia induction. (Korean J Anesthesiol 2013; 65: 14-18)

Key Words: Arthroscopy, Circuit, General anesthesia, Shoulder, Temperature.

\section{Introduction}

Hypothermia after general anesthesia is observed in approximately $60 \%$ of patients undergoing surgery [1], and results from a redistribution of body heat, reduced heat production, and a net loss of heat to the environment $[2,3]$. Furthermore, perioperative hypothermia increases the risks of myocardial ischemia [4], excessive blood loss [5], surgical wound infection, and prolonged hospitalization [6].

Perioperative hypothermia can develop easily during shoulder arthroscopy, because cold irrigation can directly influence core body temperature $[7,8]$. The uses of warmed irrigation fluid [7] or a forced-air warming blanket [8] have been reported to decrease perioperative hypothermia during

Received: October 8, 2012. Revised: 1st, November 26, 2012; 2nd, December 24, 2012; 3rd, December 25, 2012. Accepted: December 30 , 2012. Corresponding author: Hyun Jeong Kwak, M.D., Department of Anesthesiology and Pain Medicine, Gachon University Gil Medical Center, 1198, Guwol-dong, Namdong-gu, Incheon 405-760, Korea. Tel: 82-32-460-3637, Fax: 82-32-469-6319, E-mail: hyun615@gilhospital.com (c) This is an open-access article distributed under the terms of the Creative Commons Attribution Non-Commercial License (http:// creativecommons.org/licenses/by-nc/3.0/), which permits unrestricted non-commercial use, distribution, and reproduction in any medium, provided the original work is properly cited. 
arthroscopic shoulder surgery. However, blurring of visual field caused by warmed fluid during arthroscopy is of concern. On the other hand, it was recently reported that active warming and humidification of inspired gases helps maintain core body temperature and reduces blood loss during spine surgery [9], but the efficacy of active warming and the humidification of inspired gases during general anesthesia is debatable. We hypothesized that the use of a humidifier and an electrically heated circuit (HHC) would attenuate decreases in core body temperature during shoulder arthroscopy under general anesthesia. Accordingly, we prospectively evaluated whether the active warming and humidification of inspired gases would reduce decreases in core body temperature and the incidence of intraoperative hypothermia in patients undergoing arthroscopic shoulder surgery under general anesthesia.

\section{Materials and Methods}

After obtaining institutional review board approval for the study protocol, we obtained written informed consent from all patients. Forty adult patients of American Society of Anesthesiologists physical status I-II scheduled to undergo elective arthroscopic shoulder surgery were enrolled in this prospective randomized study. The patients with a body temperature above $37.5^{\circ} \mathrm{C}$, patients with uncontrolled hypertension or diabetes mellitus, and those converted to an open procedure were excluded. The primary study outcome was core body temperature at $60 \mathrm{~min}$ after anesthesia induction. Based on the results of a previous study [8], the sample size required to demonstrate a mean difference in core body temperature of $0.4^{\circ} \mathrm{C}$ with an expected $\mathrm{SD}$ of 0.38 , at an $\alpha$ of 0.05 , and a power $(1-\beta)$ of $80 \%$ was 16 patients per group. In order to compensate for unexpected losses, 20 patients were recruited for each group. Patients were randomized to receive ventilation via the conventional respiratory circuit (control group, $\mathrm{n}=20$ ) without airway warming, or to receive ventilation via a HHC (heated group, $\mathrm{n}=20$ ). Airway gas was warmed using a HHC (Anesthesia controller and A4488 Heated and humidified anesthesia breathing circuit ${ }^{\mathrm{TM}}$, Acemedical, Seoul, Korea).

All patients were premedicated with intramuscular midazolam $2 \mathrm{mg}$ and glycopyrrolate $0.2 \mathrm{mg} 1 \mathrm{~h}$ before anesthesia. Anesthesia was induced with intravenous lidocaine $40 \mathrm{mg}$, propofol $2 \mathrm{mg} / \mathrm{kg}$, and rocuronium $0.6 \mathrm{mg} / \mathrm{kg}$. After intubation, lungs were ventilated at a tidal volume of $8-10 \mathrm{ml} / \mathrm{kg}$ at a respiratory rate of $8-12$ breaths/min with no external positive end-expiratory pressure, to maintain an end-tidal carbon dioxide concentration of $30-35 \mathrm{mmHg}$ for $50 \%$ inspired oxygen at a fresh gas flow rate of $3 \mathrm{~L} / \mathrm{min}$. Inspired sevoflurane concentrations were adjusted to maintain a bispectral index (BIS) score between 40 and 55. At 15 min after anesthesia induction, patients were placed in the $70^{\circ}$ upright position using a beachchair (Allen ${ }^{\circledR}$ Lift-Assist ${ }^{\circledR}$ Beach Chair, Allen Medical Systems, Acton, USA). All surgical procedures were performed by one senior surgeon. Hypotension was defined as an MAP of $<60 \mathrm{~mm}$ $\mathrm{Hg}$ or of $<80 \%$ of baseline at $5 \mathrm{~min}$ after anesthesia induction in the supine position. Incidences of hypotension were recorded and treated with intravenous ephedrine $5 \mathrm{mg}$ or phenylephrine $50 \mu \mathrm{g}$, as appropriate.

Esophageal temperature (recorded as core temperature) was measured using an Esophageal stethoscope fitted with a temperature sensor (DeRoyal Inc., Powell, TN, USA). Core temperatures were monitored and recorded using DatexOhmeda AS/3 modules (GE Healthcare, Helsinki, Finland). Arteriovenous perfusion of fingertips was evaluated using the skin surface temperature gradient (forearm to fingertips) $\left(\operatorname{Grad}_{\mathrm{F}-\mathrm{F}}\right)$. Skin temperature probes were attached to the mid forearm and to the index finger tip opposite the nail bed without an IV cannula on the non-operative side. Room temperature was maintained at $23-24^{\circ} \mathrm{C}$ throughout, and when core temperature fell below $35^{\circ} \mathrm{C}$, warm-cotton blankets were applied. Fluids were not warmed. Hemodynamic data, core temperatures, and $\mathrm{Grad}_{\mathrm{F}-\mathrm{F}}$ values were measured in the supine position at $5 \mathrm{~min}$ after anesthesia induction (baseline values) and in the sitting position at $15 \mathrm{~min}$ intervals from $15 \mathrm{~min}$ after anesthesia induction to the end of the surgery.

Body temperatures were also measured in the postanesthesia care unit (PACU) using a tympanic thermometer (ThermoScan IRT 1020, Braun, Germany). Post anesthesia shivering was documented visually by two anesthesiologists and by two specified members of recovery room staff, who were unaware of group allocations. Shivering was defined as readily detectable fasciculations or tremors of the face, trunk, or limbs for a minimum of 15 sec. In the PACU, a forced-air warmer (WarmTouch ${ }^{\circledR}$, Mallinckrodt Medical Inc., St. Luis, MO, USA) was applied to patients with tympanic temperature below $36^{\circ} \mathrm{C}$.

SPSS 13.0 (SPSS Inc, Chicago, IL, USA) was used for the statistical analyses. Values are expressed as means \pm SD or numbers of patients. Data normality was tested using the Kolmogorov-Smirnov test, and normally distributed continuous variables were compared using the independent $t$-test or by repeated measures analysis of variance (ANOVA) with Bonferronis correction. Statistical significance was accepted for $\mathrm{P}$ values of $<0.05$.

\section{Results}

No significant differences were observed between patient characteristics or induction profiles in the control and heated groups (Table 1). The incidences of hypotension in the control and heated groups were $30 \%(6 / 20)$ and $25 \%(5 / 20)$, respecti- 
vely, which were not significantly different. Seven patients in the control group and 5 patients in the heated group were noted to suffer from shivering in the PACU (Table 1). No patient received a transfusion.

Core temperature was significantly higher in the heated group than in the control group at 75, 90, 105 and $120 \mathrm{~min}$ after anesthesia induction. When compared with baseline values, core temperatures in both groups decreased significantly from $30 \mathrm{~min}$ after anesthesia induction (Fig. 1). No significant intergroup difference was found between skin surface temperature gradient $\left(\mathrm{Grad}_{\mathrm{F}-\mathrm{F}}\right)$ values. $\mathrm{Grad}_{\mathrm{F}-\mathrm{F}}$ in the heated group increased significantly from 75 min after anesthesia induction versus baseline (Fig. 1).

Table 1. Patient Characteristics and Induction Profiles

\begin{tabular}{lccc}
\hline & $\begin{array}{c}\text { Control } \\
(\mathrm{n}=20)\end{array}$ & $\begin{array}{c}\text { Heated } \\
(\mathrm{n}=20)\end{array}$ & P value \\
\hline Age (yr) & $47.5 \pm 16.6$ & $50.4 \pm 14.1$ & 0.549 \\
Sex (M/F) & $14 / 6$ & $12 / 8$ & 0.741 \\
Weight (kg) & $67.0 \pm 11.5$ & $66.3 \pm 11.8$ & 0.841 \\
Operation time (min) & $125 \pm 48$ & $129 \pm 50$ & 0.790 \\
Co-existing disease & & & 0.907 \\
$\quad$ Hypertension & $5(25)$ & $7(35)$ & \\
$\quad$ Diabetes mellitus & $1(5)$ & $1(5)$ & \\
Hypotension during induction & $6(30)$ & $5(25)$ & 1.000 \\
$\quad$ Treated with ephedrine & $4(20)$ & $3(10)$ & \\
$\quad$ Treated with phenylephrine & $2(10)$ & $2(10)$ & 0.886 \\
Total intravenous fluid (ml) & $613(298)$ & $600(272)$ & 0.481 \\
Total irrigation fluid (L) & $7.0[2.1-12.0]$ & $6.6[1.8-20.0]$ & 0.731 \\
Shivering in PACU & $7(35 \%)$ & $5(25 \%)$ & 0.730 \\
\hline
\end{tabular}

Values are means \pm SDs, medians [ranges], or numbers of patients (\%). Control: patients treated using a conventional respiratory circuit, Heated: patients treated using a humidifier and heating circuit. PACU: post anesthetic care unit.

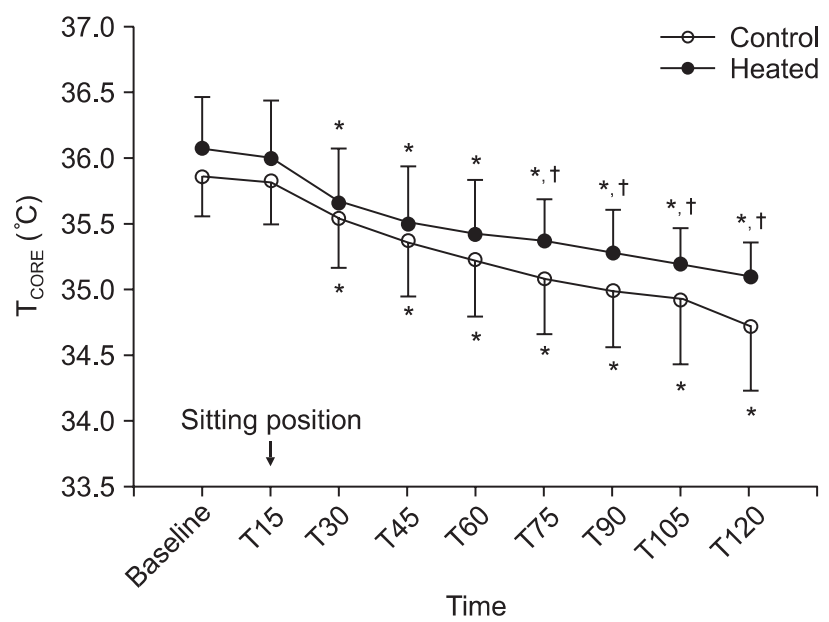

Minimum core temperatures recorded for each patient during surgery are summarized in Table 2. Hypothermia, which was defined as lower than $36^{\circ} \mathrm{C}$ occurred in all 40 patients, but the distributions of minimum temperatures in the two groups were not significantly different. The incidence of profound hypothermia, defined as lower than $35^{\circ} \mathrm{C}$, was not significantly different in the two groups.

The changes in mean arterial pressures (MAP) and heart rates (HR) are shown in Fig. 2. MAP and HR were comparable in the two groups during the study period. However, MAP in the control group was significantly lower than baseline at 15 min after induction, and in the heated group was significantly lower at 15 and 30 min after induction.

\section{Discussion}

In this study, we found that the use of a humidified and electrically heated circuit (HHC) reduced falls in core temperature from 75 min after anesthesia induction during arthroscopic shoulder surgery, but that it did not reduce the incidence of

Table 2. Minimum Temperatures during Shoulder Arthroscopy

\begin{tabular}{lcc}
\hline & $\begin{array}{c}\text { Control } \\
(\mathrm{n}=20)\end{array}$ & $\begin{array}{c}\text { Heated } \\
(\mathrm{n}=20)\end{array}$ \\
\hline Normothermia $\left(\geq 36.0^{\circ} \mathrm{C}\right)$ & 0 & 0 \\
Mild hypothermia $\left(35.5-35.9^{\circ} \mathrm{C}\right)$ & 3 & 4 \\
Moderate hypothermia $\left(35.0-35.4^{\circ} \mathrm{C}\right)$ & 8 & 11 \\
Profound hypothermia $\left(34.5-34.9^{\circ} \mathrm{C}\right)$ & 9 & 5 \\
\hline
\end{tabular}

Values are numbers of patients. Control: patients treated using a conventional respiratory circuit, Heated: patients treated using a humidifier and heating circuit. No significant intergroup differences were found ( $\mathrm{P}$ $=0.415$ ).

Fig. 1. Changes in core temperature $\left(\mathrm{T}_{\mathrm{CORE}}\right)$ and skin surface temperature gradient (forearm to fingertip) $\left(\mathrm{Grad}_{\mathrm{F}-\mathrm{F}}\right)$ in patient using a conventional respiratory circuit $(\bigcirc)$ or an electrically heated circuit $(\mathcal{)})$ during shoulder arthroscopy. Error bars represent standard deviations. Baseline: 5 min after anesthesia induction, T15-120: 15-120 min after anesthesia induction. $* \mathrm{P}<0.05$ versus baseline values within the group, ${ }^{\dagger} \mathrm{P}<0.05$ versus the control group. 

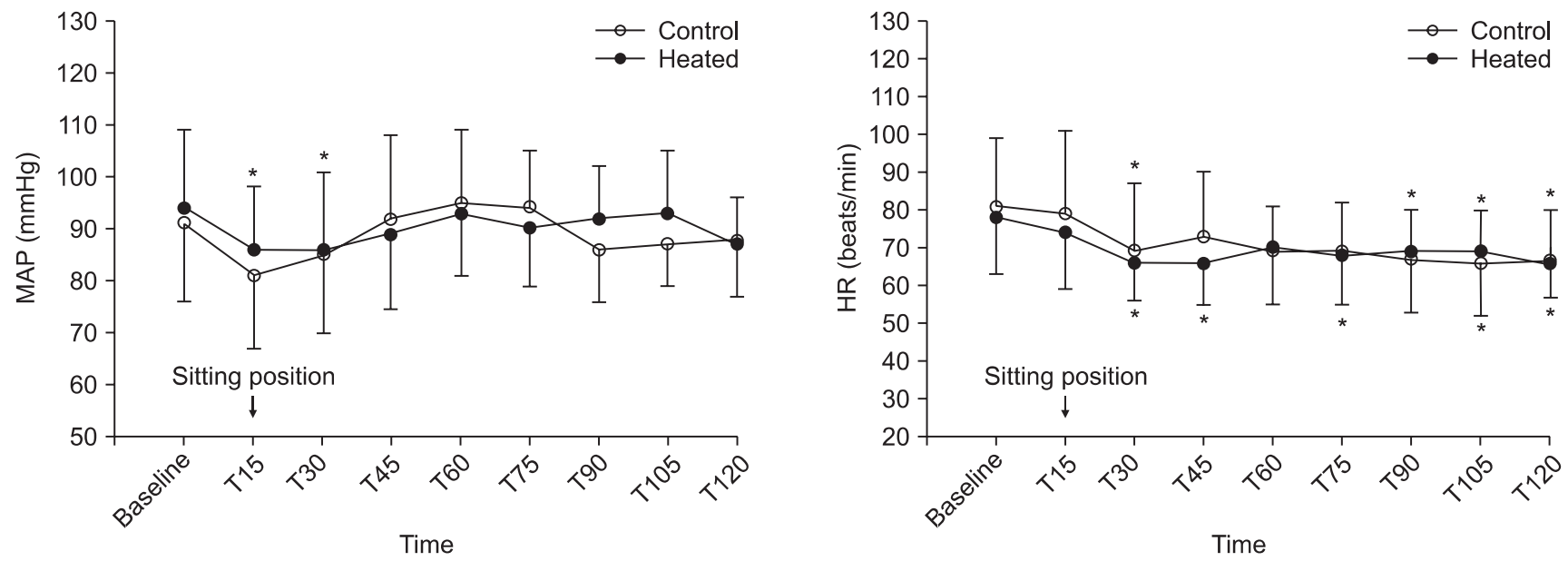

Fig. 2. Changes in mean arterial pressure (MAP) and heart rate (HR) during shoulder arthroscopy in patient using a conventional respiratory circuit (O) or an electrically heated circuit ( ). Error bars represent standard deviations. Baseline: 5 min after anesthesia induction, T15-120: 15-120 min after anesthesia induction. ${ }^{*} \mathrm{P}<0.05$ versus baseline values within the group.

intraoperative hypothermia or postoperative shivering.

Hypothermia is a known consequence of arthroscopic shoulder surgery. Even perioperative mild hypothermia, defined as a $1-3^{\circ} \mathrm{C}$ decrease in normal core temperature $\left(37^{\circ} \mathrm{C}\right)$, has been reported to have adverse effects [10,11]. General anesthesia is known to cause a core temperature reduction of about $0.5^{\circ} \mathrm{C}$ [12]. On the other hand, unintentional hypothermia after general anesthesia develops in three distinct phases $[2,3]$ : 1) An initial rapid decrease caused by heat redistribution from the central to the peripheral compartment; 2) a gradual decline during the next 3 to 4 hours because metabolic heat production fails to cope with heat losses; 3 ) a plateauing of core temperature due to reduced cutaneous heat loss and the development of thermoregulatory vasoconstriction. We undertook this study to explore the hypothesis that active warming and humidification of inspired gases would influence body heat redistribution, reduce heat loss from the respiratory tract, and inhibit thermoregulatory vasoconstriction during shoulder arthroscopy using room temperature irrigation fluids, and thus, reduce reductions in core temperature.

In the present study, room temperature irrigation fluids were used to ensure clear vision without a tourniquet, which could have exposed the intramedullary vascular system, and thus, damaged multiple small vessels. In addition, cold fluid could accumulate in soft tissues and by absorption affect the systemic circulation. Furthermore, the shoulder joint is close to the body core, and thus, irrigation fluid has a direct effect on core temperature.

The HHC unit used in this study adds moisture and heat to inspired air using temperature regulated water reservoirs, and presumably reduces evaporative process from the surfaces of airway mucous membranes and prevents energy loss [13]. Our results showed that use of this unit did not prevent a fall in core temperature, but it was found to attenuate reductions in core temperature from $75 \mathrm{~min}$ after anesthesia induction, which is consistent that found by Lee et al. [9]. In this previous study, it was found that the use of a HHC did not prevent a temperature fall but that it helped maintain body temperature $\left(35.9 \pm 0.4^{\circ} \mathrm{C}\right.$ in the study group vs. $35.4 \pm 0.5^{\circ} \mathrm{C}$ in the control group) during spine surgery [9]. Other warming strategies during shoulder arthroscopy have also been reported $[7,8]$. For example, warmed irrigation fluid has been reported to reduce the incidence of hypothermia (17.4\% vs. 91.3\%) [7], and forced-air warming has also been reported to be effective at maintaining perioperative hypothermia during sevoflurane anesthesia [8]. Because in the present study, HHC alone did not reduce the incidence of profound intraoperative hypothermia, we suggest that HHC in combination with other warming procedures, such as, warmed irrigation fluid and warmed intravenous fluid, be considered.

When we used the incidence of shivering to evaluate postoperative shivering, no significant intergroup difference was observed. However, further evaluation using a validated classification [13] is needed to elucidate the anti-shivering efficacy of HHC during shoulder arthroscopy. Furthermore, rectal temperature might provide more objective data about in core temperature changes than esophageal temperature, which is likely to be influenced by HCC settings during arthroscopic shoulder surgery. In addition, in the sitting position, more vasodilation is likely to develop in lower extremities owing to venous pooling, and thus, $\operatorname{Grad}_{\mathrm{F}-\mathrm{F}}$ values measured at toes might provide a better indicator of arteriovenous perfusion.

Some limitations in this study warrant consideration. First, we did not calculate health care utilization costs. Although HHC units are unlikely to affect hospital stays, they are expensive, and 
thus, the overall balance between medical benefits and patient satisfaction requires scrutiny. Furthermore, although ventilatorassociated pneumonia [14] improbable after brief exposure, water condensates may reduce the functions of respiratory gas monitors and ventilators. Second, vasoconstrictors used to treat hypotension in the sitting position might influence body temperature changes, for example, ephedrine and phenylephrine have been reported to reduce core temperature falls during surgery $[15,16]$. However, this is unlikely to have affected the results of this study because the numbers of patients administered a vasoconstrictor injection during anesthesia induction were similar in the two study groups. Third, we applied a warm-cotton blanket when core temperature fell below $35.0^{\circ} \mathrm{C}$, which might have influenced our results. However, the numbers of patients that received a blanket were not significant different (5 and 9 patients in the control and heated groups, respectively, $\mathrm{P}=$ 0.320 ), and withholding blankets would have been unethical.

Summarizing, the use of a HHC did not prevent core temperature reductions during arthroscopic shoulder surgery, but did reduce core temperature falls from 75 min after anesthesia induction.

\section{References}

1. Frank SM, Shir Y, Raja SN, Fleisher LA, Beattie C. Core hypothermia and skin-surface temperature gradients. Epidural versus general anesthesia and the effects of age. Anesthesiology 1994; 80: 502-8.

2. Sessler DI, McGuire J, Moayeri A, Hynson J. Isoflurane-induced vasodilation minimally increases cutaneous heat loss. Anesthesiology 1991; 74: 226-32.

3. Matsukawa T, Sessler DI, Sessler AM, Schroeder M, Ozaki M, Kurz A, et al. Heat flow and distribution during induction of general anesthesia. Anesthesiology 1995; 82: 662-73.

4. Frank SM, Beattie C, Christopherson R, Norris EJ, Perler BA, Williams GM, et al. Unintentional hypothermia is associated with postoperative myocardial ischemia. The Perioperative Ischemia Randomized Anesthesia Trial Study Group. Anesthesiology 1993; 78: 468-76.

5. Schmied H, Kurz A, Sessler DI, Kozek S, Reiter A. Mild hypothermia increases blood loss and transfusion requirements during total hip arthroplasty. Lancet 1996; 347: 289-92.

6. Kurz A, Sessler DI, Lenhardt R. Perioperative normothermia to reduce the incidence of surgical-wound infection and shorten hospitalization. Study of wound infection and temperature group. N Engl J Med 1996; 334: 1209-15.

7. Kim YS, Lee JY, Yang SC, Song JH, Koh HS, Park WK. Comparative study of the influence of room-temperature and warmed fluid irrigation on body temperature in arthroscopic shoulder surgery. Arthroscopy 2009; 25: 24-9.

8. Yoo HS, Park SW, Yi JW, Kwon MI, Rhee YG. The effect of forced-air warming during arthroscopic shoulder surgery with general anesthesia. Arthroscopy 2009; 25: 510-4.

9. Lee HK, Jang YH, Choi KW, Lee JH. The effect of electrically heated humidifier on the body temperature and blood loss in spinal surgery under general anesthesia. Korean J Anesthesiol 2011; 61: 112-6.

10. Rajagopalan S, Mascha E, Na J, Sessler DI. The effects of mild perioperative hypothermia on blood loss and transfusion requirement. Anesthesiology 2008; 108: 71-7.

11. Leslie K, Sessler DI. Perioperative hypothermia in the high-risk surgical patient. Best Pract Res Clin Anaesthesiol 2003; 17: 485-98.

12. Deakin CD. Changes in core temperature compartment size on induction of general anaesthesia. Br J Anaesth 1998; 81: 861-4.

13. Crossley AW, Mahajan RP. The intensity of postoperative shivering is unrelated to axillary temperature. Anaesthesia 1994; 49: 205-7.

14. Kirton OC, DeHaven B, Morgan J, Morejon O, Civetta J. A prospective, randomized comparison of an in-line heat moisture exchange filter and heated wire humidifiers: rates of ventilator-associated early-onset (community-acquired) or late-onset (hospital-acquired) pneumonia and incidence of endotracheal tube occlusion. Chest 1997; 112: 1055-9.

15. Ikeda T, Ozaki M, Sessler DI, Kazama T, Ikeda K, Sato S. Intraoperative phenylephrine infusion decreases the magnitude of redistribution hypothermia. Anesth Analg 1999; 89: 462-5.

16. Jo YY, Kim JY, Kim JS, Kwon Y, Shin CS. The effect of ephedrine on intraoperative hypothermia. Korean J Anesthesiol 2011; 60: 250-4. 